\title{
Estimating the Level of Motor Memory Using Suggested E-Measurement and Its Relation with Decisions of Kata Judges in Karate
}

\author{
Ahmed Abdel-Fattah Hossen*, Hesham Hegazy Abdel-Hamed**
}

\begin{abstract}
:
The research aims for designing an electronic scale for the motor memory to identify the differences between judges in evaluating the level of kata, in addition to estimating the level of the motor memory of the judges of kata in karate through using the proposed electronic scale. Also to identify the relation between the levels of motor memory and the decisions of the judges of kata in karate. Researchers used the descriptive method and the sample was selected randomly from the new referees that are registered in the Egyptian federation of Karate $(n=20)$.

The results of the research proved the validity of the proposed electronic scale in evaluating the level of motor memory of kata judges in karate, also the presence of significant differences between judges in assessing the level of kata, in addition to the presence of significant differences between the kata judges in the level of motor memory. Also the presence of a directly proportional relationship between the level of motor memory and the decisions of the judges of kata in karate.
\end{abstract}

Keywords: Motor Memory - E-measurement - Kata Judges in Karate.

\section{Problem of Research:}

Recently, there has been a great interest in mental process in the sports field due to its importance in understanding and comprehending the physical performance which will help to promote the performance level as well as the learning processes that will lead to reaching the highest proper level in the practiced physical activity.

The memory is the ability of selective representation for information which uniquely represents a distinguished specific experience and keep these information in an organized way of the current memory structure and reproduce some or all these information in a specific time in the future under specific conditions or circumstances.(24: 219)

In general memory refers to different types of special and general mental activities, memory

\footnotetext{
* Lecturer in curriculum and teaching methods of physical education, Faculty of Physical Education, Mansoura University, Egypt.

** Lecturer in curriculum and teaching methods of physical education, Faculty of Physical Education, Mansoura University, Egypt.
}

has a dual structure that is divided into short term and long term where it can be described as a process of finding continuous changing in the brain results from unfixed or transferred stimulus.(17: 68)

Almegharbel quoted from Mansour et al (2003) mentioning that motor memory has a special importance in sports games and in some tasks which needs motor skills or motor creation such as karate that needs motor sequence to elaborate skill performance, this way is related to the players' ability to remember movements that were previously learned .(4: 7)

If remembering is an important process for karate players, it is much more important for kata judges specially as they directly and fully depend on memory in their judgments and decisions concerning kata players performance as both competitors perform their own kata consecutively on carpet then both players go outside playground and wait for judges decision by rising blue or red flag to announce the winner (Aka-Aw).

Karate law 2011 determines that the assessment of motor performance in karate depends on jury 
method, the arbitrators committee consists of (5) judges, the chairman of kata judges sits on outside edge of playground facing competitors and the other four judges sitting in the four angles of the playground comers that allows them to have the best vision. Every judge has two flags, one is blue and the other is red then competitors have to perform their different kata in order, once the performance of kata is over, it can never be repeated (30).

Researchers asked if it is reasonable that judges still remember the details of performance of each player with its positives and negatives to announce the final result after both players has already finished their performance?

The temporary or short term memory that save the form of players performance can keep information for short time relatively, therefore specialist differ to determine it . however it lies mostly in the range of 5-30 seconds only. $(29: 15)(17: 71)(20)(28: 10)(1: 8)(18: 27)$ (3:40)

Practical researches had shown that the ability to retrieve previous experiences in the form of mental images is different according to individuals it means that mental images of any scene for example differs in terms of clarity, accuracy and compliance to the fact that when two persons have witnessed the same situation under the same conditions. $(3: 25)$

Here, the research problem is clear that the time which the judge can keep information and performance details in his short term memory does not exceed (30) seconds maximum at a time when performance time of less kata is more than (40) seconds and maximum (150) seconds for only one player. So this time will double in addition to time spent in the entry and exist of both players which confirm the importance of memory for kata judges in karate and its effect on judges' decisions. Thus researchers felt the necessity to identify the relationship between motor memory and results of kata judges decisions in karate as to the importance of their critical judgments to identify the win or loss of a player or a country. The importance of research is clear in terms of the practical aspect of designing an E-test to measure the motor memory and apply it to evaluate the memory level of kata judges, and its relationship with assessment results.

\section{Aim of Research:}

- Designing an e-scale for motor memory

- Identifying the differences between judges in assessing the level of kata performance

- Assessing the level of motor memory of kata judges in karate by using the suggested e-scale

- Identifying the relationship between the level of motor memory and the decisions of kata judges in karate

\section{Questions of Research :}

- Are there significant differences among judges in assessing the level of kata?

- Are there differences among kata judges in the levels of motor memory by using the suggested e-scale?

- Is there a relation between the level of memory and the decisions of kata judges in karate?

\section{Procedures of Research:}

Method:- Researchers used the descriptive method.

Sample:- sample was selected randomly among new judges who are registered in the Egyptian Karate federation $(n=20)$.

\section{Designing the suggested e-scale to assess the level of motor memory:}

\section{Determine the main aspects of e-scale:}

As a result of survey for studies in the field of educational and psychological measurements and memory in the sport field, specialized reference, internet and interviews with specialists in the field of psychology and karate to identify memory tests, the following variables were determined (concentration, attention, conception, calling, observation, realization, error discrimination and speed of decisionmaking) In terms of these tests, researchers determined a group of testes such as (concentration grid - attention- concentration order of kata images - memory game, paired similar images - determining differences among similar images) and they were presented to experts in psychology and karate to determine 
the suitability of these tests that were prepared in paper form to suit the specialization of karate.

\section{Preparing e-scale:}

Designing the form to register data, judges decisions and e-scale results then taking experts opinion. The desired images were produced and processed by using (Adobe Photo Shop) program and using (Macromedia Author ware) Program version (7.02) to produce the suggested e-measure.(21)

\section{Components of the suggested e-measure to assess motor memory level of kata judges:-}

The scale consists of (5) figured e-tests as follows:

First test (concentration grid) where a board from (63 digital images) is presented to the tested judge for $(150 \mathrm{~S})$ where he needs to click with the mouse on a group of numbers according to a specific order then the number of correct and incorrect responses are calculated in addition to the actual time of finishing the test.

Second test (attentional concentration) where it is needed to concentrate in a board to identify places of presented images of skills that consist of (16 images) for (15 s) and then disappear then the judge needs to determine the places of a specific skill using the mouse within ( $5 \mathrm{~s})$, then the number of correct and incorrect responses are calculated in addition to the actual time of finishing the test.

Third test consists of two parts of kata images the first part of kata (Heian Godan) where a group of images are presented on a board (33 non-ordered images ) then the judge needs to put these images in order by using the mouse through dragging and dropping each image in its right order during $(150 \mathrm{~s})$ then the number of correct and incorrect responses are calculated in addition to the actual time of finishing the test, the second part of kata (Heian Youndan) where a group of images are presented on a board (31 non-ordered images ) then the judge needs to put these images in order by using the mouse through dragging and dropping each image in its right order during $(150 \mathrm{~s})$ then the number of correct and incorrect responses are calculated in addition to the actual time of finishing the test.

Fourth test (memory game) where a board of (20 disappeared images) are presented to the judge who tries to discover similar images by using the mouse and pair them through clicking them in righteous order. then the number of correct and incorrect responses are calculated in addition to the actual time of finishing the test.

Fifth test (difference among images) where two similar images are presented to the judge who has to point out the differences between these 2 images during $(10 \mathrm{~s})$ where he need to click with the mouse on the existing differences on the second image then the number of differences and the time spent in the test are calculated.

It is also confirmed that the computer system chooses these tests randomly to avoid the information transmission among the sample population.

Designing criteria of the displayed items are characterized with harmony, propriety of color, clarity and attraction. Judges depended on using the mouse easily with no need for previous knowledge with using computer. The most important instructions were added in front of each test to confirm what is needed to be done from the sample population. Also the time count and the sample responses were monitored on the screen clearly. The size of electronic copy of the e-measurement program (16.4 MB) is very appropriate and easy for usage and transmission. Also the scale is so easy to use due to its clear instructions and its suitability to all kinds of pc operating systems.

Two pilot studies were conducted to confirm the validity of the suggested scale to be applied on the sample population as follows:

\section{First pilot study:}

E-scale was applied on a random sample of (10) karate players (black belt) in order to identify the clarity of instructions and sentences and the ease of understanding the tests in addition to the absence of any difficulties or problems during applying the e-scale. 


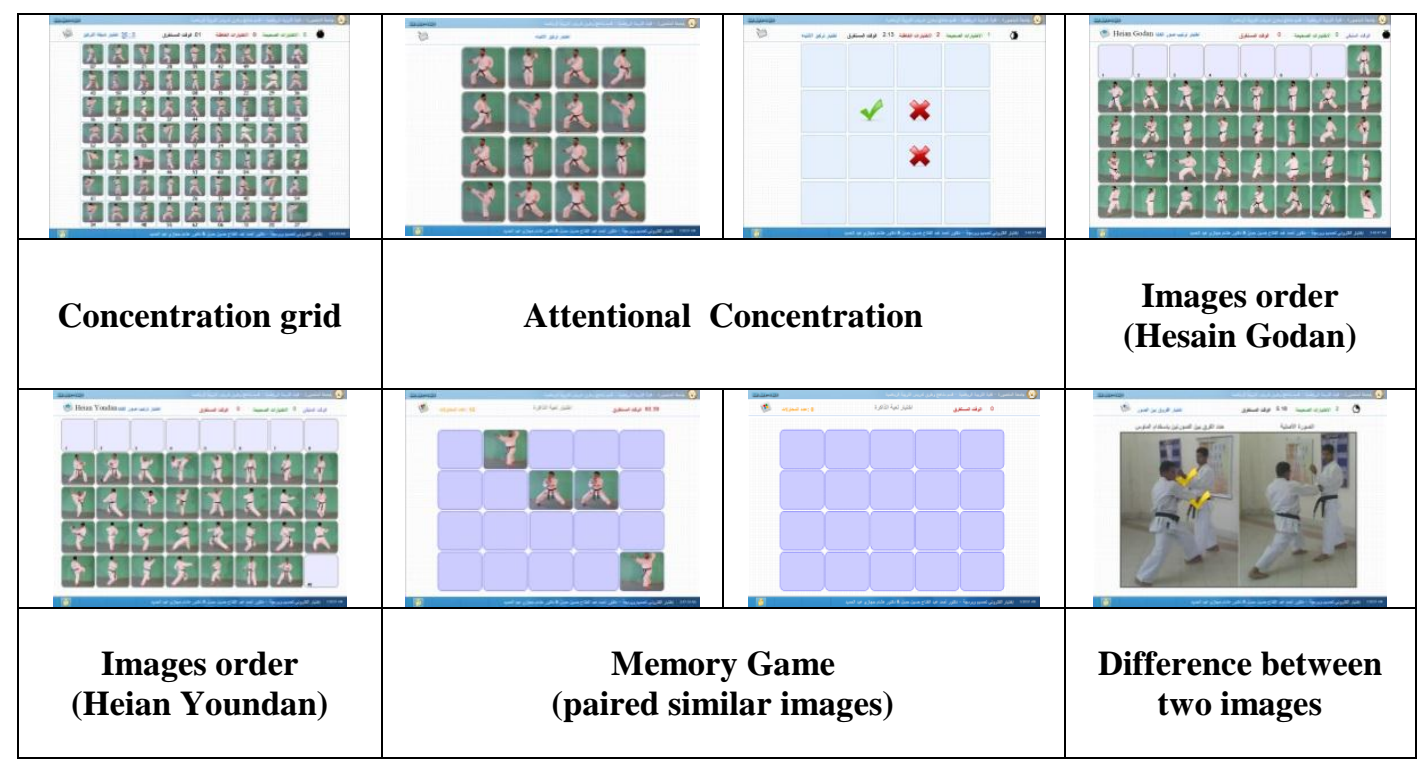

Figure (1) models of suggested e- measure

\section{Second pilot study:}

E-scale was applied on a random sample of karate players (black belt) $n=30$ who fitted the conditions of acceptance as new judges to calculate the validity coefficient of the test.

\section{Reliability:}

To find reliability coefficient, the researchers used test application and re-application after (30) days on the same sample in order to find correlation coefficient between results of first and second measurements as shown in table(1)

Table (1)

Reliability coefficients of suggested e-measure $t$ assess motor memory $n=30$

\begin{tabular}{|c|c|c|c|c|c|c|c|c|c|}
\hline \multirow{2}{*}{$\begin{array}{l}\mathbf{n} \\
\mathbf{o}\end{array}$} & \multirow{2}{*}{\multicolumn{2}{|c|}{ Test }} & \multirow{2}{*}{ Variables } & \multirow{2}{*}{$\begin{array}{l}\text { Measuremen } \\
\text { t unit }\end{array}$} & \multicolumn{2}{|c|}{ First measure } & \multicolumn{2}{|c|}{ Second measure } & \multirow{2}{*}{$\begin{array}{l}\text { Correlation } \\
\text { coefficient }\end{array}$} \\
\hline & & & & & mean & elevation & mean & elevation & \\
\hline \multirow{2}{*}{1.} & \multirow{2}{*}{\multicolumn{2}{|c|}{ concentration grid }} & $\begin{array}{c}\text { Incorrect } \\
\text { choice }\end{array}$ & Number & 1.067 & 1.181 & 0.833 & 0.934 & $* 0.705$ \\
\hline & & & time & Second & 117.732 & 19.543 & 109.417 & 19.580 & $* 0.949$ \\
\hline \multirow{3}{*}{2.} & \multirow{3}{*}{\multicolumn{2}{|c|}{ Attentional- concentration }} & $\begin{array}{c}\text { Incorrect } \\
\text { choice }\end{array}$ & Number & 1.200 & 0.792 & 1.400 & 0.952 & $* 0.690$ \\
\hline & & & correct choice & Number & 2.567 & 2.290 & 2.667 & 2.006 & $* 0.760$ \\
\hline & & & time & Second & 4.249 & 0.601 & 4.353 & 0.653 & $* 0.720$ \\
\hline \multirow{2}{*}{3.} & \multirow{2}{*}{$\begin{array}{c}\text { order } \\
\text { kata } \\
\text { images }\end{array}$} & $\begin{array}{c}\text { (Heian } \\
\text { Youndan) }\end{array}$ & time & Second & 86.924 & 34.587 & 77.601 & 33.136 & *0.943 \\
\hline & & (Heian Godan) & time & Second & 99.171 & 26.238 & 88.452 & 28.891 & $* 0.914$ \\
\hline \multirow{2}{*}{4.} & \multirow{2}{*}{\multicolumn{2}{|c|}{ memory game }} & time & Second & 87.082 & 39.217 & 81.414 & 31.101 & $* 0.888$ \\
\hline & & & tries & Number & 33.533 & 12.126 & 34.933 & 9.092 & $* 0.797$ \\
\hline \multirow{2}{*}{5.} & \multirow{2}{*}{\multicolumn{2}{|c|}{$\begin{array}{c}\text { Differences among similar } \\
\text { images }\end{array}$}} & correct choice & Number & 2.600 & 1.332 & 3.133 & 1.056 & $* 0.725$ \\
\hline & & & time & Second & 7.584 & 1.468 & 7.556 & 1.541 & $* 0.731$ \\
\hline
\end{tabular}

* Correlation coefficient (r) value / $0.05=0.361$

Table (1) shows the presence of significant positive relationship at the level of (0.05) between the first and second application in all tests of the suggested e-scale to assess motor memory which confirms the readability of the scale.

\section{Validity:-}

The researchers used the method of terminal comparison to calculate the validity through comparing high and low degrees of pilot study sample population $n=30$. Researchers compared between the maximum and minimum quarts -of degrees for this group as shown in table (2). 
Table (2)

Validity coefficients of suggested e-measure to assess motor memory $n=8$

\begin{tabular}{|c|c|c|c|c|c|c|c|c|c|}
\hline \multirow{2}{*}{ No } & \multirow{2}{*}{\multicolumn{2}{|c|}{ Test }} & \multirow{2}{*}{ Variables } & \multirow{2}{*}{$\begin{array}{l}\text { Measurement } \\
\text { unit }\end{array}$} & \multicolumn{2}{|c|}{$\begin{array}{l}\text { Minimum } \\
\text { quarter }\end{array}$} & \multicolumn{2}{|c|}{$\begin{array}{c}\text { Maximum } \\
\text { quarter }\end{array}$} & \multirow{2}{*}{ (t) } \\
\hline & & & & & mean & $\begin{array}{c}\text { elevati } \\
\text { on }\end{array}$ & mean & $\begin{array}{c}\text { elevati } \\
\text { on }\end{array}$ & \\
\hline \multirow[t]{2}{*}{1.} & \multirow{2}{*}{\multicolumn{2}{|c|}{ concentration grid }} & $\begin{array}{c}\begin{array}{c}\text { Incorrect } \\
\text { choice }\end{array} \\
\end{array}$ & number & 2.625 & 0.992 & 0.000 & 0.000 & $7.483^{*}$ \\
\hline & & & time & Second & 143.655 & 5.821 & 94.249 & 10.943 & $11.274^{*}$ \\
\hline \multirow{3}{*}{2.} & \multirow{3}{*}{\multicolumn{2}{|c|}{$\begin{array}{l}\text { Attentional } \\
\text { concentration }\end{array}$}} & $\begin{array}{c}\text { Incorrect } \\
\text { choice }\end{array}$ & number & 0.250 & 0.463 & 2.500 & 0.500 & $9.340^{*}$ \\
\hline & & & $\begin{array}{c}\begin{array}{c}\text { correct } \\
\text { choice }\end{array} \\
\end{array}$ & Number & 5.500 & 0.866 & 0.500 & 0.535 & $13.896^{*}$ \\
\hline & & & time & Second & 5.099 & 0.433 & 3.303 & 0.653 & $6.480^{*}$ \\
\hline \multirow{2}{*}{3.} & \multirow{2}{*}{$\begin{array}{c}\text { order } \\
\text { kata } \\
\text { images }\end{array}$} & $\begin{array}{c}\text { (Heian } \\
\text { Youndan) } \\
\end{array}$ & time & Second & 126.064 & 18.759 & 55.402 & 9.420 & $* 9.521$ \\
\hline & & $\begin{array}{c}\text { (Heian } \\
\text { Godan) }\end{array}$ & time & Second & 147.846 & 4.427 & 51.038 & 11.684 & $21.914^{*}$ \\
\hline \multirow{2}{*}{4.} & \multirow{2}{*}{\multicolumn{2}{|c|}{ memory game }} & time & Second & 107.919 & 9.055 & 51.406 & 3.553 & $16.432 *$ \\
\hline & & & tries & Number & 46.875 & 4.885 & 25.375 & 2.722 & $10.875^{*}$ \\
\hline \multirow[t]{2}{*}{5.} & \multirow{2}{*}{\multicolumn{2}{|c|}{$\begin{array}{l}\text { Differences among } \\
\text { similar images }\end{array}$}} & $\begin{array}{l}\text { correct } \\
\text { choice }\end{array}$ & Number & 2.000 & 0.535 & 4.500 & 0.866 & $6.948^{*}$ \\
\hline & & & time & Second & 9.369 & 0.349 & 5.339 & 0.677 & $14.972 *$ \\
\hline
\end{tabular}

* Coefficient $(t)$ value / $0.05=1.895$

Table (2) shows that there are significant differences at the level of $(0.05)$ between the minimum and maximum quarts of degrees of pilot study in the suggested e-scale to assess the motor memory on behalf of maximum quart which proves the scale validity.

\section{Implementation of Basic study:}

The basic study was implemented on judges during championships where (5) lab-tops and (2) two rooms were used for doing the test, the scale and aims of application as well as instructions of tests were presented to research population in addition to the objective of each test through a lecture that took $(15 \mathrm{~m})$. Tests were conducted in an appropriate room that allows the existence of judges and computers within suitable distance to prevent any discussions among judges and not to allow them to meet the untested judges to prevent information exchange among them. Researchers recorded degrees of each test for each judge in the registration form.

Discussion of results :

Presentation and discussion of correlation results among judges decisions in assessing kata level: 
Table (3)

Correlation coefficient among judges results in first and second assessment/n-1=59

\begin{tabular}{|c|c|c|c|}
\hline No. & Correlation coefficient $(\mathbf{r})$ value & Determination coefficient & Correlation rate \\
\hline $\mathbf{1}$ & $* 0.429$ & 0.184 & $18.37 \%$ \\
\hline $\mathbf{2}$ & $* 0.711$ & 0.506 & $50.57 \%$ \\
\hline $\mathbf{3}$ & $* 0.256$ & 0.065 & $6.54 \%$ \\
\hline $\mathbf{4}$ & $* 0.462$ & 0.214 & $21.35 \%$ \\
\hline $\mathbf{5}$ & $* 0.398$ & 0.159 & $15.85 \%$ \\
\hline $\mathbf{6}$ & $* 0.790$ & 0.624 & $62.44 \%$ \\
\hline 7 & $* 0.787$ & 0.619 & $61.89 \%$ \\
\hline $\mathbf{8}$ & $* 0.763$ & 0.582 & $58.24 \%$ \\
\hline $\mathbf{9}$ & $* 0.454$ & 0.206 & $20.58 \%$ \\
\hline $\mathbf{1 0}$ & $* 0.426$ & 0.182 & $18.16 \%$ \\
\hline $\mathbf{1 1}$ & $* 0.709$ & 0.502 & $50.21 \%$ \\
\hline $\mathbf{1 2}$ & $* 0.440$ & 0.194 & $19.40 \%$ \\
\hline $\mathbf{1 3}$ & $* 0.821$ & 0.675 & $67.46 \%$ \\
\hline $\mathbf{1 4}$ & $* 0.729$ & 0.532 & $53.17 \%$ \\
\hline $\mathbf{1 5}$ & $* 0.718$ & 0.515 & $51.49 \%$ \\
\hline $\mathbf{1 6}$ & $* 0.749$ & 0.561 & $56.13 \%$ \\
\hline $\mathbf{1 7}$ & $* 0.457$ & 0.209 & $20.87 \%$ \\
\hline $\mathbf{1 8}$ & $* 0.853$ & 0.728 & $72.76 \%$ \\
\hline $\mathbf{1 9}$ & $* 0.725$ & 0.525 & $52.52 \%$ \\
\hline $\mathbf{2 0}$ & $* 0.469$ & 0.220 & $22.04 \%$ \\
\hline
\end{tabular}

* Correlation coefficient $(r)$ value / $0.05=0.254$

Table (3) shows the presence of significant correlation between first and second assessments of karate judges in studied kata, where the correlation ratio of (11) judges is larger than $(50 \%)$ and less than $(50 \%)$ for (9) judges. This can be referred to the difference between first and second assessment of judges in different rates. this is due to the followed method in arbitration which depends on the motor memory of judges, where they assess each kata after complete watching and give a full degree depending on their ability of remembering performance details and comparing it with the best performance that exist in their memory. This agrees with what Mohammed (2007) said that researches showed that the ability of retrieving previous experiences in form of mental image differs according to individual differences, that mental images of scene differ in its clarity, accuracy and accordance to fact that two persons saw the same scene under one condition, also, the time factor has a role that students has forgotten the information that were introduced to them in courses of architecture theories as experiences had showed that every time that is passed on all form of information received ( images- written and oral sentences) the rate of remembering is less.(20: 3,7)

Mosab (2009) confirms that the role of shortterm memory system is determined in interpretation of instant strong realization of events that sensory system receives. This system is a process of storing incoming information from stimuli that the individual is exposed to in different behavioral situation to benefit from in other situations with consideration that this process has limited possibilities as it represents time between introduction and appearance of stimuli in situations and retries them which doesn't exceed one minute. If current information are in stimulated awareness, find 
information is not spent time. Thus stored mattes in short-term store should be dragged quickly and efficiency where it could not retries information from short- term memory after (1520) Second, unless memorize or transfer them to the long - term memory. If there is no attention to new information it is forgetting and faded. However it individual watches it transferred from calculator memory to short - term memory or working memory, that storing energy of this memory is limited .if information is coded in this memory it will keep attention concentration or transfers this information to the long- term memory . As well as the presence of a high relationship between memory and attention, where difference in level of attention intensity can lead to difference in level of remembering intensity. Information which takes more concentration in attention could be stored in memory effetely. Therefore remembering and retrieving will be fast and easy. (18: 27-30)

This answers the first research question "Are there significant differences among judges in assessing kata level" where there are differences.

Consequently, the results of table (3) judges' are divided into two categories. First category (high group) includes judges there determent factor is more than $(50 \%)$ and second category (low group) include judges their determination factor is less than $(50 \%)$.

\section{Discussion results of differences among kata judges in level of motor memory using suggested e- measure:}

Table (4)

Significant differences between high and low level of judges in t test degrees of suggested e-scale to assess motor memory $n=8$

\begin{tabular}{|c|c|c|c|c|c|c|c|}
\hline \multirow{2}{*}{ No } & \multirow{2}{*}{\multicolumn{2}{|c|}{ Test }} & \multicolumn{2}{|c|}{ High group } & \multicolumn{2}{|c|}{ low group } & \multirow{2}{*}{ (t) } \\
\hline & & & Mean & elevation & mean & elevation & \\
\hline 1 & \multicolumn{2}{|c|}{ concentration grid } & 62.991 & 3.412 & 51.331 & 4.757 & $* 2.197$ \\
\hline 2 & \multicolumn{2}{|c|}{ attention- concentration } & 66.705 & 9.347 & 30.397 & 8.933 & $* 2.553$ \\
\hline 3 & \multirow{2}{*}{$\begin{array}{l}\text { order kata } \\
\text { images }\end{array}$} & $\begin{array}{c}\text { (Heian } \\
\text { Youndan) }\end{array}$ & 55.622 & 7.630 & 45.674 & 9.532 & $* 2.601$ \\
\hline 4 & & (Heian Godan) & 54.940 & 9.533 & 45.654 & 7.712 & $* 2.360$ \\
\hline 5 & \multicolumn{2}{|c|}{ memory game } & 59.105 & 6.172 & 35.381 & 6.981 & $* 2.507$ \\
\hline 6 & \multicolumn{2}{|c|}{$\begin{array}{c}\text { differences among similar } \\
\text { images }\end{array}$} & 55.000 & 6.65 & 47.89 & 5.21 & $* 2.620$ \\
\hline 7 & \multicolumn{2}{|c|}{ Total } & 350.493 & 14.233 & 252.435 & 18.379 & $* 4.456$ \\
\hline
\end{tabular}

* Coefficient $(t)$ value / $0.05=2.101$ T test degrees (0: 100

Table (4) shows that there are significant differences between judges results of high and low groups in $(\mathrm{t})$ degrees of suggested e-scale results to assess the motor memory where all calculated values of $(t)$ were greater than indexed at the level of significance (0.05) for all items of scale on behalf of high group which refers to the importance of motor memory of kata judges in karate for taking the right decisions. This agrees with what Emad Ramadan (2001) said which is quoted from (Fischoff) \& et, al that decisions-making includes the search for relevant information about the results and alternative choices, which will probably be negative or positive, and difficulty of deciding when decisions have multiple elements and attributes because of the ability of storing information is limited in the short term memory that does not allow people to easily remember, collect and compare all attributes of choices and they were unable to remember, may remember a few little information does not allow the decisionmaking.(10)

And this replies to the second and third research questions.

\section{Conclusions:}

In terms of the research aims and sample and the research method and through the presentation and discussion of results, researches concluded the following: 
1. The validity of the suggested e-scale to assess motor memory level of kata judges in karate.

2. There are differences among judges in the assessment of kata level

3. There are differences among kata judges in the level of motor memory.

4. There is a direct relationship between the level of motor memory and the decisions of kata judges in karate.

\section{Recommendations:}

1. Using the suggested e-motor memory measure to assess the motor memory level of kata judges.

2. Insert the suggested e-motor memory measure within tests of kata judge's acceptance in karate.

3. Put programs for developing the motor memory of kata judges in karate.

4. Using the suggested e-measure to assess motor memory within programs of learning and training of karate.

5. Make and designee similar e-measure for motor memory measurement in the other sports.

\section{References:}

1. Abdul Wahab Al Mesbahi: The importance of aid in remembering the great Holy Quran from the perspective of supervisors and teachers Quranic episodes, the world body for the memorization of the Koran in the Abstracts of the Third Scientific Forum, Jeddah, September 2006, p. 8, Available at http://www.saaid.net/book/9/2204.doc pag 8(2006)

2. Ahmed Amin Fawzy: Sports Psychology principles and applications, Alfania for Printing and Publishing, Alexandria,p6.(1992)

3. Alan Baddeley: Human Memory theory and Practice, Allyn and Bacon, London page40, Available at

http://cliff.uconn.edu/Baddeley1990_34.pdf page 40

4. Ali Mustafa Almogharbel: The Effectiveness of Recreational Sports Program On The Motor Memory For The Junior in the sport of karate, Master Thesis, Faculty of Physical Education, Tanta University, p7(2003)
5. Bsmaa Adam:immediate visual recognition and its relationship to cognitive speed (field study on a sample of students from the Faculty of Education, University of Damascus), Damascus University Journal - Volume 23 Issue II, p 388, available at:http://www.reefnet.gov.sy/booksproject/jame 3a/7tarbaoy/207/12-adam.pdf pag 388 (2007)

6. Catherine Tallon-Baudry,1 Olivier Bertrand,1 and Catherine Fischer2: Oscillatory Synchrony between Human Extrastriate Areas during Visual Short-Term Memory Maintenance, The Journal of Neuroscience, Vol. 21 RC177 1 of 5. (2001)

7.Chih-Lin Chang, Kai-Way Li, Yung-Tsan Jou,Hsu-Chang Pan and Tai-Yen Hsu: The Influence of Gender and Age on the Visual Codes Working Memory and the Display Duration - A Case Study of Fencers, Engineering Psychology and Cognitive Ergonomics, Lecture Notes in Computer Science, Volume 5639/2009, 139-148, DOI: 10.1007/978-3-642-02728-4_15 (2009)

8. Corrigan. Ralph: Karate (Made Easy), published by sterling publishing company, Inc, New York, p76 (1995)

9. Dan , Bradley: Step by Step Karate skills , Hamlyn company, Hong Kong, p12 (1988)

10. Emad Ramadan Suleiman: difficulties in decision-making Available at: http://emadramadan.blogspot.com/04/2011/blog-

post_1985.html 18/2/2012

11. Eman Hassan Jbaili, Leila Abbas Solomon: the impact of the use of teaching methods at the level of performance and memory to motor skill handstand forward roll, the scientific journal of Physical Education and Sport, No. 21. (2001)

12. Lester B. Mayersa; Thomas S. Redickb; Sheila H. Chiffrillerc; Ashley N. Simonec; Keith R. Terrafortec: Working memory capacity among collegiate student athletes: Effects of sport-related head contacts, concussions, and working memory demands, Journal of Clinical and Experimental Neuropsychology Volume 33, Issue 5, First published on 07 January 2011 Pages 532 - 537 (2011)

13. Marwa Emad Eddin: How to Develop your Memory, Dar Altlaa, Cairo, p13 (1994) 
14. Measuring Memory: Available at: (2006) http://www.camden.rutgers.edu/ bwhitlow/Cou rses/ Experimental/Ch8memory.pdf

15. Mohamed Alarabi Shamon: Sports Psychology and Psychological Measurement, Center for the Book Publishing, Cairo,p381,391. (1998)

16. Mohammad Sami Almsidy: The impact of different ways to Learning Dynamic exercises on the memory and cognitive organization in motor sport karate, Ph.D. thesis, Faculty of Physical Education in Cairo, Helwan University, P4 (1990)

17. Mohammed Hashim Ryan: Thinking Skills and Agility and Training Packages, Alflah Library for Publishing and Distribution, Amman, p68,71. (2003)

18. Musab Mohamed Shaaban Alwan: Information processing and its relationship to the ability to solve problems with high school students, Master Thesis, Faculty of Education, Islamic University in Gaza, pages 27,28,29,30 (2009)

19. Nakayama, M: Best Karate (Heian.Tekki), Kodansha, International, LTD, New York, p12 (1981)

20. Nubi Mohammed Hassan: The timeframe for the survival of the information in the memory of students of architecture (applied study on students of the decision theories of architecture at King Saud University), research published in: Journal of Engineering Research, Faculty of Engineering, University of Menoufia, Egypt, Volume 30, Issue 0.2, April 2007, p2,3,7, (2007)

21. Orson Kellogg: Authorware 5, translation of Khaled al-Amiri, et al, Dar Al Farouk for Publishing and Distribution, the first edition, Cairo. (2000)

22. Philip Alexander Furleya; Daniel Memmerta: The role of working memory in sport, International Review of Sport and Exercise Psychology, Volume 3, Issue 2,Pages 171 - 194 (2010)

23. Raja Abdul Samad Ashour: Design and rationing tests to measure the short-term memory and speed of response motor vehicle, Master Thesis, Faculty of Physical Education, Basra University, Available (2008)

24. Saleh Mohammad Ali Abu Gado: Educational Psychology, Dar march for publication and distribution, printing, Amman, Jordan, fourth edition. p219 (2005)

25. Scott W. Brown; Attentional resources in timing: Interference effects in concurrent temporal and non temporal working memory tasks, Attention, Perception, \& Psychophysics, Volume 59, Number 7, 11181140, DOI: 10.3758/BF03205526

26. Suad Mohammed Ahmed Gabr: the impact of the use of teaching strategies in different ways to remember motor in handball, the scientific journal of Physical Education and Sports, the second number. (1992)

27. Zakia Ibrahim Ahmed Kamel: The impact of the interaction of cognitive styles and teaching methods to remember motor skills to prepare for volleyball, Encyclopedia of Physical Education Research Arab World, Dar Almnaheg, Amman, (2001)

28.http://www.abegs.org/sites/APD/DocLib/1.p df pag 10

29.http://www.abegs.org/sites/Upload/DocLib

$\% 2279 / 3 \mathrm{D} \% 86 \% 9 \mathrm{D} \% 8 \mathrm{~B} \% 8 \mathrm{D} \% 8 \mathrm{~B} \% 1 \mathrm{D} 8 \% 9 \mathrm{~A}$

$\% \mathrm{D} \% 8 \mathrm{~A} \% 20 \% 9 \mathrm{D} \% 85 \% 9 \mathrm{D} \% 8 \mathrm{~B} \% 9 \mathrm{D} \% 8 \mathrm{~A} \% 7$

D\%84\%9D\%8AC\%D\%8A\%7D\%8AA\%20\%D

$\% 8 \mathrm{~A} \% 7 \mathrm{D} \% 84 \% 9 \mathrm{D} \% 85 \% 9 \mathrm{D} \% 8 \mathrm{~B} \% 9 \mathrm{D} \% 84 \% 9$

D\%88\%9D\%85\%9D\%8A\%7D\%8AA.pdf

$11 / 1 / 2011$ pag 15

30.http://www.wkf.net/index.php?option=com_ content $\&$ view $=$ article $\&$ id $=87 \&$ Itemid $=99$

$2011 / 9$ 